\title{
Measurements of the Thermophysical Properties of the API 5L X80
}

\author{
Tiago de Sousa Antonino1,2, Pablo Batista Guimarães¹, Roberto de Araújo Alécio², \\ Yogendra Prasad Yadava ${ }^{2}$, Ricardo Artur Sanguinetti Ferreira ${ }^{2 *}$ \\ ${ }^{1}$ Federal Institute of Education, Science and Technology of Pernambuco, Recife, Brazil \\ ${ }^{2}$ Federal University of Pernambuco, Department of Mechanical Engineering, Recife, Brazil \\ Email: ${ }^{*}$ ras@ufpe.br
}

Received 28 March 2014; revised 3 May 2014; accepted 30 May 2014

Copyright (C) 2014 by authors and Scientific Research Publishing Inc.

This work is licensed under the Creative Commons Attribution International License (CC BY). http://creativecommons.org/licenses/by/4.0/

C. (†) Open Access

\section{Abstract}

The thermophysical properties of API 5L X80 steel were experimentally measured, in order to use these in computational models to determine the temperature field in welded joints. In this work, values of thermal expansion coefficient, specific heat, thermal diffusivity and thermal conductivity were experimentally obtained as a function of temperature. The thermal expansion coefficient was determined at temperatures of $20^{\circ} \mathrm{C}$ to $1200^{\circ} \mathrm{C}$ in a dilatometer DIL $402 \mathrm{PC}$. The specific heat was determined on a differential scanning calorimeter at temperatures between $300^{\circ} \mathrm{C}$ and $1200^{\circ} \mathrm{C}$. The diffusivity and thermal conductivity were determined in the temperature range $100^{\circ} \mathrm{C}$ to $800^{\circ} \mathrm{C}$ in a $457 \mathrm{LFA}$ diffusivimeter using laser flash technique. The thermal expansion coefficient remained approximately with constant value of $8.5 \times 10^{-6} \mathrm{~K}^{-1}$ and suffered two falls reaching values $-25 \times 10^{-6} \mathrm{~K}^{-1}$ and $-50 \times 10^{-6} \mathrm{~K}^{-1}$ in the stages of heating and cooling respectively. It was observed for this material, minimum and maximum values of specific heat equal to $0.571 \mathrm{~J} / \mathrm{gK}$ and $1.084 \mathrm{~J} / \mathrm{gK}$ at temperatures of $300^{\circ} \mathrm{C}$ and $720^{\circ} \mathrm{C}$, respectively. The behavior of thermal diffusivity and thermal conductivity in the temperature range $100^{\circ} \mathrm{C}$ to $800^{\circ} \mathrm{C}$ tends to decrease with increasing temperature. Based on the measured properties, computational modeling of the temperature field can be numerically obtained with better accuracy.

\section{Keywords}

Thermophysical Properties, API 5L X80 Steel, Measurements

\section{Introduction}

The correlation between microstructure and mechanical properties in high strength low alloy (HSLA) steels has

${ }^{*}$ Corresponding author.

How to cite this paper: de Sousa Antonino, T., Guimarães, P.B., de Araújo Alécio, R., Yadava, Y.P. and Ferreira, R.A.S. (2014) Measurements of the Thermophysical Properties of the API 5L X80. Materials Sciences and Applications, 5, 617-627. 
been analyzed by many researchers [1] [2]. However, the thermophysical properties of these microalloyed steels have been little studied.

In recent years, in order to increase product quality and reduce cost, the industry has placed more and more emphasis on advanced numerical simulation technology to better understand the critical parts of the thermal evolution, stress and microstructure during welding, casting and other manufacturing processes [3]. Although the numerical models are quite advanced and have a high potential for improving the quality of products, leading to a better understanding of materials behavior, their success depends, in large part, on an accurate thermophysical property database. However, the required input data of thermophysical properties necessary for accurate simulations are frequently nonexistents or unreliables at elevated temperature [3]-[5] for many alloys of interest for engineering. Considering the improved performance of computers with a cost relatively low, threedimensional modeling become an attractive possibility for the design and optimization of welded structures with respect to the residual stresses and deformations [5].

Several approaches of two-dimensional analysis have been performed using well known materials. However, in many cases, a two-dimensional model is not suitable. The "nature" of the welding process often requires a three-dimensional analysis [3]-[7]. These models may include non-linearities in the material such as thermophysical properties (thermal conductivity, specific heat, thermal expansion coefficient, etc.), all temperature dependent. It is also necessary to consider the complex of thermal and mechanical contours conditions and latent heat [4]. The distribution of the heat coming from the fusion zone to the base metal results in high temperature gradients, which also produces considerable variations in the mechanical properties of the material [7]-[9].

In the analysis of heat transfer problems, it is necessary to know the various thermophysical properties of matter, which are divided into two distinct categories [10]: the transport properties and the thermodynamic properties. The transport properties including diffusion coefficients rate as the thermal conductivity $(K)$, which represents the ease with which the heat conduction in the material, being defined by Fourier's law (Equation (1))

$$
K_{X}=-\frac{q^{\prime \prime} x}{\partial T / \partial X}
$$

where $q^{\prime \prime} x$ is the heat flux in the $x$ direction and $(\partial T / \partial X)$ is the temperature gradient in the same direction. Similar definitions are associated with other directions, but in an isotropic material the thermal conductivity is independent of direction.

Richter [11] and Powell [12] have reported physical properties as a function of temperature for a number of different steels. The thermal conductivity of steel alloys diverges when temperature is decreased. The pure iron having the highest thermal conductivity is followed by carbon steels, alloy steels and then by high-alloy steels. High-alloy steels have lower thermal conductivity at ambient temperatures than at high temperatures. At higher temperatures, in austenite domain, all the alloys have similar thermal conductivities.

In addition to the transport properties, there are thermodynamic properties, which are related to the equilibrium state of a system. Two of these properties widely used in heat transfer analysis are the density $(\rho)$ and specific heat $\left(c_{p}\right)$. The product $\rho c_{p}\left[\mathrm{~J} / \mathrm{m}^{3} \cdot \mathrm{K}\right]$, called volumetric heat capacity, is the ability of a material to store thermal energy [10].

The ratio between the thermal conductivity and volumetric heat capacity is called thermal diffusivity. This is an important property that measures the ability of a material to conduct thermal energy relative to its ability to store it, and thus the response speed of the material in relation to changes in thermal conditions [10].

The specific heat is understood as the amount of heat needed to change one degree in the temperature of a unit mass. This property is crucial to determine the amount of energy to be added or removed in the processes of heating and cooling [10].

\section{Material and Methods}

The material used in this work was the API 5L X80 steel with a thickness of $19 \mathrm{~mm}$. This steel with wide application in the oil and gas has a chemical composition shown in Table 1.

The thermal expansion coefficient $(\alpha)$, specific heat $\left(c_{p}\right)$, thermal diffusivity $(\lambda)$ and thermal conductivity $(K)$ of API 5L X80 steel were experimentally measured as a function of temperature. 
Table 1. Chemical composition of API 5L X80 steel (\% mass).

\begin{tabular}{ccccccccc}
\hline $\mathrm{C}$ & $\mathrm{S}$ & $\mathrm{N}$ & $\mathrm{Al}$ & $\mathrm{Si}$ & $\mathrm{P}$ & $\mathrm{Ti}$ & $\mathrm{V}$ \\
\hline 0.03 & 0.003 & 0.0054 & 0.027 & 0.21 & 0.013 & 0.017 & 0.023 \\
$\mathrm{Cr}$ & $\mathrm{Mn}$ & $\mathrm{Ni}$ & $\mathrm{Cu}$ & $\mathrm{Nb}$ & $\mathrm{Mo}$ & $\mathrm{B}$ & $\mathrm{Ca}$ & 0.0032 \\
0.158 & 1.78 & 0.013 & 0.008 & 0.071 & 0.183 & 0.0001 & 0.12 \\
\hline
\end{tabular}

\subsection{Thermal Expansion Coefficient}

To obtain the thermal expansion coefficient of API 5L X80 steel, dilatometry tests were carried out in a DIL 402 PC dilatometer.

For these tests, cylindrical specimens with $5 \mathrm{~mm}$ of diameter and $25 \mathrm{~mm}$ of length were manufactured from API 5L X80 steel. These samples were subjected to heating and cooling steps, in order to obtain the phase transformation temperatures of the steel and the thermal expansion coefficient of the material with temperature.

The DIL 402 PC dilatometer has the following technical specifications:

temperature range: from room temperature to $1200^{\circ} \mathrm{C}$;

heating rates: $0.01 \mathrm{~K} / \mathrm{min}$ to $50 \mathrm{~K} / \mathrm{min}$;

measuring range: $500 \mu \mathrm{m} / 5000 \mu \mathrm{m}$;

> sample length: $50 \mathrm{~mm}$ (máx.);

$>$ sample diameter: $12 \mathrm{~mm}$ (máx.);

$>$ resolution $(\Delta \mathbf{L}): 8 \mathrm{~nm}$.

\subsection{Specific Heat}

The measurement of the specific heat of API 5L X80 steel was carried out in the Differential Scanning Calorimetry (DSC)/Differential Thermal Analysis (DTA)-LABSYS evo.

The specific heat $C_{P}$ of a sample is defined as: $C_{P}=(\partial H / \partial T)_{P}$. Three different methods can be used for the determination of specific heat: the continuous, the stepwise and the drop methods. The first two methods can be used for $C_{P}$ determination of solids and liquids. The drop method can be only used for solids.

The stepwise method gives usually a better result, but takes more time to implement. In this study stepwise method was used to measure the specific heat.

To make quantitative measurements the $3 D-C_{P}$ sensor needs to be calibrated. The calibration has been done using sapphire $\alpha-\mathrm{Al}_{2} \mathrm{O}_{3}$ as standard because data on this material are easily available in the literature. Thus, the procedure for measuring the specific heat of a material sample follows 3 steps:

1) Measurement of a blank;

2) Measurement of a calibration reference (sapphire standard);

3) Measurement of the sample.

The calculation is the carried out in the processing section of the software using the following equation (Equation (2)):

$$
C_{P}=C_{P S} \times \frac{m_{C}\left(Q_{S}-Q_{b}\right)}{m_{S}\left(Q_{C}-Q_{b}\right)}
$$

In this equation, $Q_{b}, Q_{S}$ and $Q_{c}$ are the amplitudes of the blank, of the sample and of the calibrant respectively, all measured in $\mu V$. The $m_{c}$ and $m_{S}$ are the weights of the calibrant and the sample respectively, and $C_{P S}$ is the specific heat of calibrant.

For temperatures from $70^{\circ} \mathrm{C}$ to $1600^{\circ} \mathrm{C}$ the specific heat of the calibrant is represented by the following polynomial function (Equation (3)):

$$
C_{P S}=A_{0}+A_{1} T+A_{-2} T
$$

In this equation, $A_{0}=1,1583, A_{1}=1,0247 \mathrm{E}-4, A_{-2}=-3,9999 \mathrm{E}+4$ and $T$ is the temperature.

\subsection{Diffusivity and Thermal Conductivity}

In order to obtain the diffusivity and thermal conductivity of API 5L X80 steel a technique called laser flash was 
used in a Micro Flash LFA 457 diffusivimeter. The LFA 457 is an instrument used to measure these properties in metals, graphite, coatings, composites, ceramics, polymers, liquids and other materials.

The Flash method is used in $80 \%$ of the measured thermal diffusivity across the world and became an ASTM standard (ASTM 1461-01, 2001) [13]. When compared with the direct measurement of thermal conductivity, the advantages of this method are:

$>$ Sample geometrically simple, small size and easy to prepare;

$>$ Applicability to a wide range of diffusivity values of $0.001 \mathrm{~cm}^{2} / \mathrm{s}$ to $10 \mathrm{~cm}^{2} / \mathrm{s}$ and temperatures from $-125^{\circ} \mathrm{C}$ to $1100^{\circ} \mathrm{C}$;

$>$ Excellent accuracy;

$>$ A wide temperature range can be covered in a short period of time when a little time is required for a single measurement.

The sample is mounted in the system support which is located inside the furnace. While the sample reaches a predetermined temperature, the energy supplied by a laser pulse is absorbed by the bottom face of the sample, resulting in heating of this. The heat propagates through the sample by conduction, increasing the temperature of the upper surface. The temperature rise is measured on this face as a function of time by an infrared detector. The thermal diffusivity is calculated by the software, through mathematical models selected.

The vertical construction of the measuring unit is the primary component of the system. The laser system is mounted in a closed wrapper at the bottom. A receiver block is located above the laser system. The cylindrical sample holder (Figure 1) and its regulating device are mounted on this block. A seal enables a vacuum, or the existence of a controlled atmosphere within the furnace. The system of the furnace is raised and lowered by a mechanical jack. The laser is emitted with a wavelength in the infrared band with $1064 \mathrm{~nm}$, while the pulse width is variable. A thermocouple is placed at the side of the sample carrier tube, serving to measure the temperature inside the oven and therefore the samples. Different thermocouples may be used depending only on the temperature range of interest, and using a liquid nitrogen tank as a reference value, the infrared detector measures the temperature rise on the upper surface of the sample.

The samples used in this experiment were cylindrical with a diameter of $12.5 \mathrm{~mm}$ and a thickness of $3 \mathrm{~mm}$. The faces of these samples were coated with a graphite special ink of black color, in order to increase either the surface absorptivity, improving the absorption of the energy pulse, or the emissivity, enhancing the emission of radiation and reading the IR sensor.

At the end of the test, the results are analyzed in PROTEUS software. Here, the heating curve of each pulse can be viewed individually as well as the test conditions. The mathematical model can be chosen from among the existing or fail to choose the by software, admitting that it select the one that best matches the heating curve at each point.

\section{Results and Discussion}

The theoretical works on heat transfer in the welding process began with Rosenthal in the 40's [14] [15]. However analytical solutions of the thermal problem for welding were obtained with some simplifications, among them, the variation of thermophysical properties with temperature is neglected so the average values were adopted. Obviously, various physical properties of the material such as its thermal conductivity vary with temperature. Taking into account this variation, the problem becomes very complex or impossible, so that the analytical solution requires the use of a numerical method.

\subsection{Thermal Expansion Coefficient}

The dilatometry is one of the most powerful techniques for the study of phase transformations in solid state, because it allows the monitoring of the evolution of changes in real time in terms of dimensional changes that occur in the sample by applying athermal cycle. The applicability of dilatometry in research of phase transformation is due to the change of the specific volume of a sample during a phase transformation. When a material undergoes a phase transformation, the crystal structure changes and this is normally accompanied by a change in specific volume [16].

A graph of dilatometry as a function of temperature and time concerning a dilatometric test was carried out on API 5L X80 steel in the condition of "as received" (Figure 2).

The microstructure of the material "as received" was observed by Scanning Electron Microscopy (SEM) and 


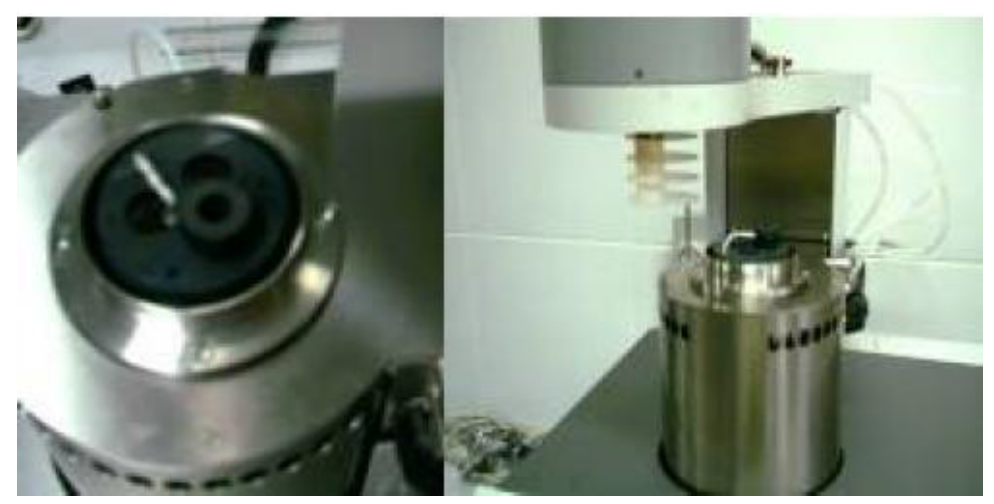

Figure 1. Sample holder.

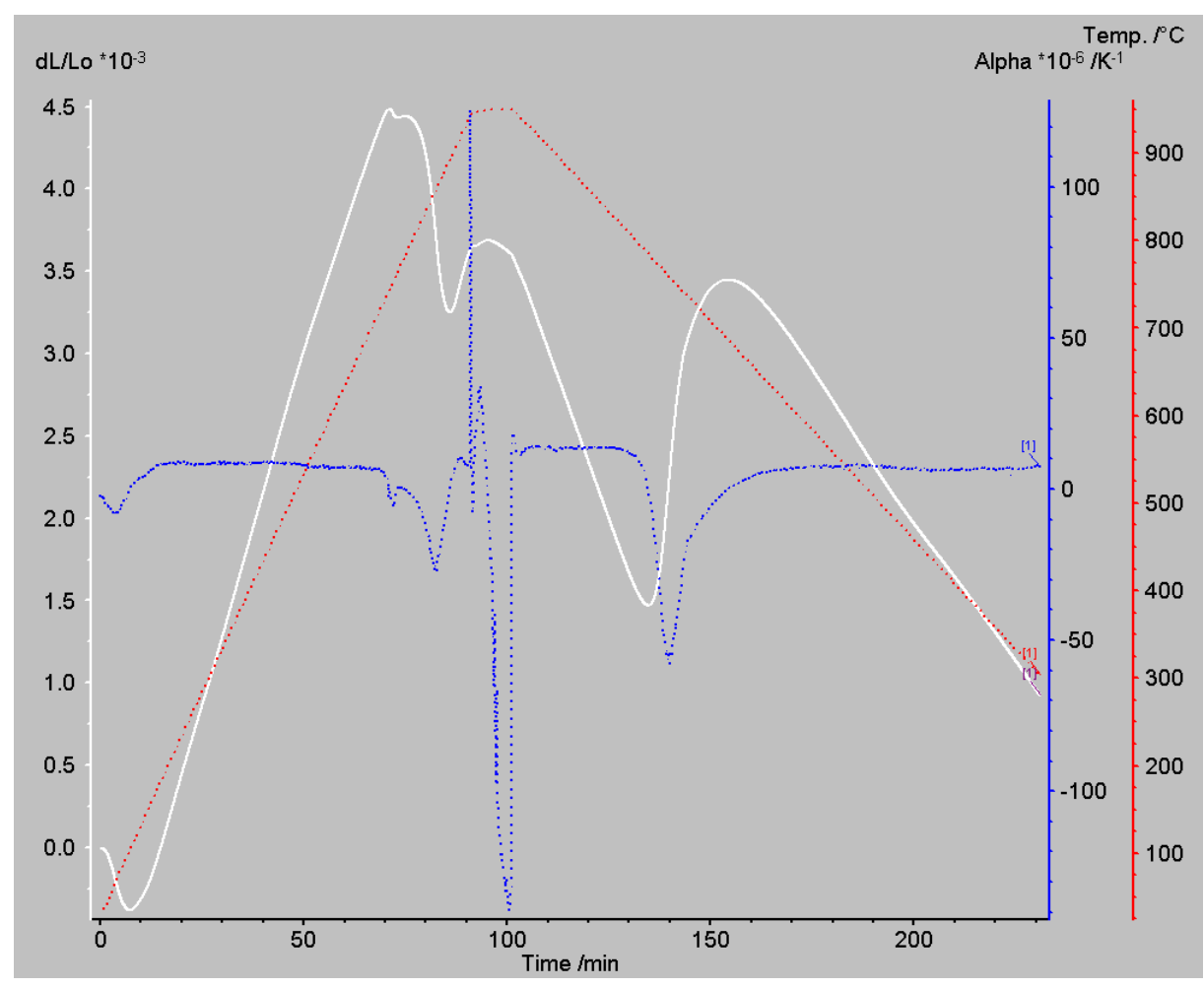

Figure 2. Measured results of the thermal expansion coefficient $\left[\mathrm{K}^{-1}\right]$ of the API $5 \mathrm{~L}$ X80 steel.

is shown in Figure 3, with increases of 4000 and 10,000X, which allowed us to characterize the constituent phases. In these micrographs, the microstructures are predominantly formed by polygonal ferrite (black ellipses). The whitish grain boundaries characterizing a solute enrichment at the grain boundaries (blue ellipses) also been observed. In addition, it is also possible to observe the presence of perlite (orange ellipses) in some grain boundaries.

In the dilatometric test, the material was heated with a heating rate of $10^{\circ} \mathrm{C} / \mathrm{min}$ until a temperature of $950^{\circ} \mathrm{C}$ and then it was maintained at this temperature for 10 minutes to ensure complete austenitizing, and finally it was cooled with a cooling rate $5^{\circ} \mathrm{C} / \mathrm{min}$ to the temperature of $300^{\circ} \mathrm{C}$ (red curve, Figure 2). In addition to obtaining the phase transformation temperature of the steel during thermal cycling (white curve, Figure 2), the dilatometric technique can also be used for measuring the thermal expansion coefficient of this material as a function of temperature (blue curve, Figure 2).

During the heating step, the thermal expansion coefficient of the steel remains approximately constant with a value of $8.5 \times 10^{-6} \mathrm{~K}^{-1}$, however, the thermal expansion coefficient is dropped reaching a minimum of approx- 


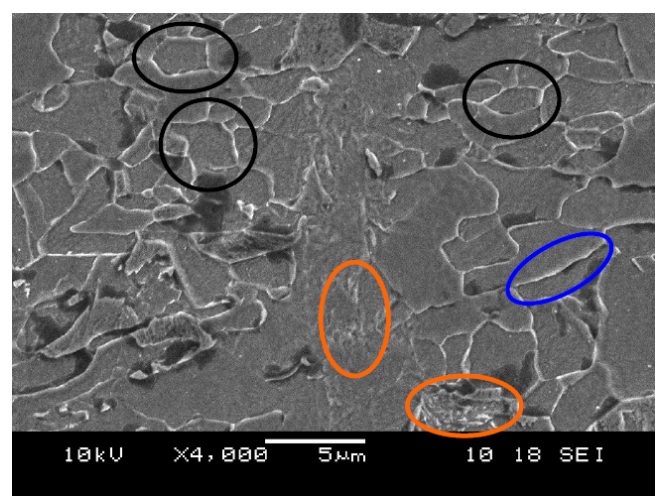

(a)

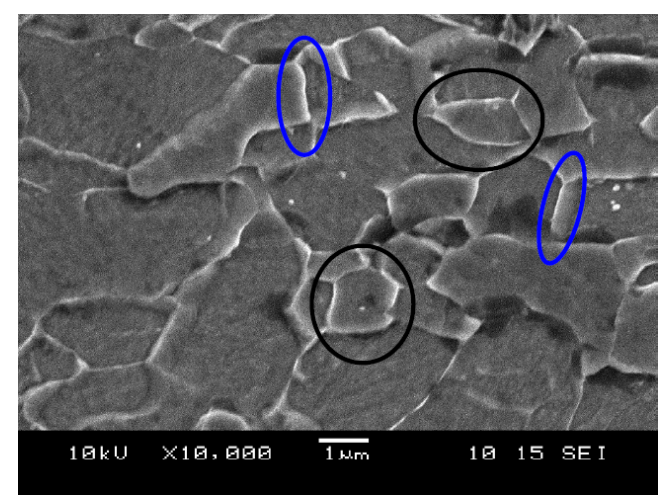

(b)

Figure 3. SEM micrographs of API 5L X80 steel in condition as received. (a) 4000X and (b) 10,000X.

imately $-25 \times 10^{-6} \mathrm{~K}^{-1}$ at temperature of $890^{\circ} \mathrm{C}$, due to the occurrence of the phase transformation $\alpha \rightarrow \gamma$ in the temperature range of $730^{\circ} \mathrm{C}$ to $890^{\circ} \mathrm{C}$. At the end of this transformation, the thermal expansion coefficient becomes to the value of $8.5 \times 10^{-6} \mathrm{~K}^{-1}$.

During the cooling step, the thermal expansion coefficient of the steel remains approximately constant with a value of $8.5 \times 10^{-6} \mathrm{~K}^{-1}$, however, the thermal expansion coefficient undergoes another drop reaching a minimum of approximately $-50 \times 10^{-6} \mathrm{~K}^{-1}$ at temperature of $685^{\circ} \mathrm{C}$, due to the occurrence of the phase transformation $\gamma \rightarrow \alpha$ in the temperature range of $785^{\circ} \mathrm{C}$ to $685^{\circ} \mathrm{C}$. At the end of this transformation, the thermal expansion coefficient becomes to the value of $8.5 \times 10^{-6} \mathrm{~K}^{-1}$.

It is clearly shown that between the heating step and cooling step has a region of disturbance in the behavior of the thermal expansion coefficient of the steel (higher peaks). The reasons for this may be also associated to phase transformations (austenite decomposition), which may have occurred during the isothermal stage $950^{\circ} \mathrm{C}$.

\subsection{Specific Heat}

The measured results of the specific heat are shown in the graph below (Figure 4). In this work, values of specific heat of API 5L X80 steel have been measured in the range $300^{\circ} \mathrm{C}$ to $1200^{\circ} \mathrm{C}$ with a step $(\Delta T)$ of $20 \mathrm{~K}$. It is observed (Figure 4) for this material, in the considered range, minimum and maximum values of specific heat equal to $0.571 \mathrm{~J} / \mathrm{gK}$ and $1.084 \mathrm{~J} / \mathrm{gK}$ at temperatures of $300^{\circ} \mathrm{C}$ and $720^{\circ} \mathrm{C}$, respectively. According to Pedrosa [17], this peak that appears in the curves $\alpha$ versus $T$ and $C_{P}$ versus $T$, is due to the occurrence of phase transformation $(\alpha \leftrightarrow \gamma)$ in steel. It is clearly observed that the peak present at the $C_{P}$ versus $T$ curve (Figure 4) shows a maximum value of $C_{P}$ equal to $1.084 \mathrm{~J} / \mathrm{gK}$ at $720^{\circ} \mathrm{C}$ and then drops to $0.603 \mathrm{~J} / \mathrm{gK}$ at $880^{\circ} \mathrm{C}$. This behavior shows the occurrence of the phase transformation $\alpha \rightarrow \gamma$ in this temperature range, being in agreement with the dilatometric curve (Figure 2).

Li [3], studying the thermophysical properties of the AISI 4320 and 4130 steels found the same behavior of the $C_{P}$ versus $T$ curve. The curve has a significant endothermic peak starting around $700^{\circ} \mathrm{C}$. This peak represents the solid state austenite phase transformation and extends to around $825^{\circ} \mathrm{C}$. A similar behavior of $C_{P}$ versus $T$ curve is also found for pure iron (Figure 5). Here the peak starting at around $725^{\circ} \mathrm{C}$ and extends to around $925^{\circ} \mathrm{C}$.

A similar behavior of the curve $C_{P}$ versus $T$ but with different values of specific heat was obtained [18] in a low carbon steel $(0.1 \% \mathrm{C})$. The same happened with Deng [19] studying two carbon steel of $0.15 \% \mathrm{C}$ and $0.45 \%$ C.

Attarha and Sattari-Far [20], studying a carbon steel with $0.15 \%$ C, found results similar to those obtained in this work until the temperature of $400^{\circ} \mathrm{C}$. Above $400^{\circ} \mathrm{C}$ their results were very different with a maximum value to the specific heat equal of $0.863 \mathrm{~J} / \mathrm{gK}$ to $1300^{\circ} \mathrm{C}$. Very different results were found by Shan [21], who used these properties in a stainless steel which is not transformed in the temperature range of our study.

\subsection{Thermal Diffusivity and Thermal Conductivity}

For all measurements, the software PROTEUS showed that the model that best represented the data obtained in 


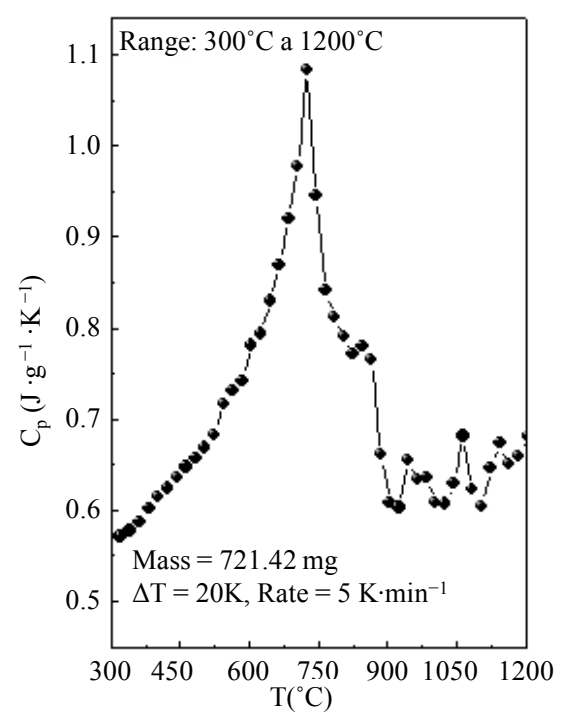

Figure 4. Measured results of the specific heat $[\mathrm{J} / \mathrm{gK}]$ of the API 5L X80 steel.

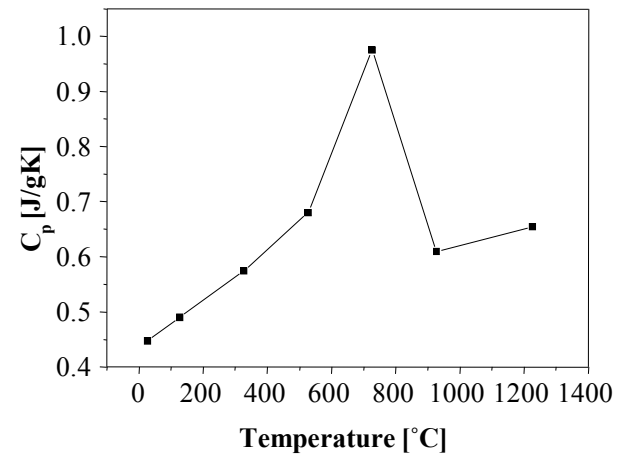

(a)

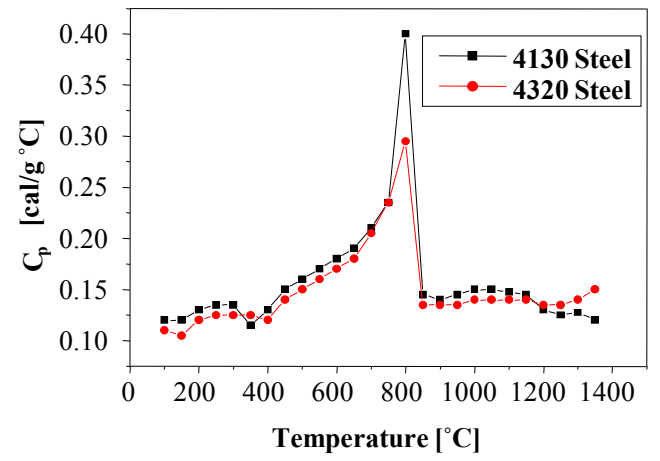

(b)

Figure 5. Measured results of the specific heat $[\mathrm{J} / \mathrm{gK}]$ a) in the pure iron and b) in the AISI 4130 and 4320 steels, adapted from [3].

this study was the Cape and Lehman model with correction pulse. The mathematical model of Cape and Lehman [22] is more complex than that of Parker [23], and use more complex and comprehensive considerations:

Two-dimensional conduction with symmetry in respect to the central axis;

The energy absorbed by the sample as a source-term in the energy equation;

Uniform energy flow, completely absorbed at $x=0$;

Losses heat surfaces taken into account as a linearized radiation term.

Using a sample of thickness $L$ and radius $r_{0}$, originally at temperature $T_{0}$, the model is given by (Equation (4)):

$$
\begin{aligned}
& \frac{1}{\alpha} \frac{\partial \delta(r, x, t)}{\partial t}=\frac{\partial^{2} \delta}{\partial r^{2}}+\frac{1}{r} \frac{\partial \delta}{\partial r}+\frac{\partial^{2} \delta}{\partial x^{2}}+\frac{q(r, x, t)}{K} \text { em } 0<x<L, 0<r<r_{0}, t>0 \\
& -\frac{\partial \delta}{\partial x}+v_{x} \delta=0 \quad \text { em } \quad x=0,0<r<r_{0}, t>0 \\
& \frac{\partial \delta}{\partial x}+v_{x} \delta=0 \quad \text { em } x=0,0<r<r_{0}, t>0 \\
& \frac{\partial \delta}{\partial r}+v_{r} \delta=0 \quad \text { em } r=r_{0}, 0<x<L, t>0 \\
& \delta=0 \quad \text { para } t=0,0<x<L, 0<r<r_{0}
\end{aligned}
$$


where: $\delta(r, x, t)=T(r, x, t)-T_{0}$

$$
v_{x, r}=\frac{4 \sigma \epsilon_{x, r} T_{0}^{3}}{K}
$$

In Equation (5), $\sigma$ is the Stefan-Boltzmann constant $\left(\sigma=5.67 \times 10^{-8} \mathrm{~W} / \mathrm{m}^{2} \mathrm{~K}^{4}\right)$ and $\varepsilon$ is the emissivity of the surface.

The graphics generated by the diffusivity and thermal conductivity were calculated by software based on each pulse done on the samples (Figure 6). Through these, it can be seen that any point may have any inadequacy in the result of measurement.

In this work, the diffusivity and thermal conductivity values of API 5L X80 steel were measured in the range $100^{\circ} \mathrm{C}$ to $800^{\circ} \mathrm{C}$ with a step $(\Delta T) 50 \mathrm{~K}$. It is observed (Figure 6) within the range considered that this material has minimum and maximum values of diffusivity equal to $3 \mathrm{~J} / \mathrm{gK}$, and $13 \mathrm{~J} / \mathrm{gK}$ at temperatures of $750^{\circ} \mathrm{C}$ and $100^{\circ} \mathrm{C}$, respectively. The thermal conductivity also shows minimum and maximum values equal to $13 \mathrm{~W} / \mathrm{mK}$ and $52 \mathrm{~W} / \mathrm{mK}$ at the same temperatures. It is clearly shown that two of the points obtained at a temperature of $500^{\circ} \mathrm{C}$ does not fit the trend of the points and should be disregarded. The reasons for this may due to fluctuations in the mains voltage, which may have interfered with the signals from the various instruments in operation. A similar behavior $K$ versus $T$ curve is also found for pure iron (Figure 7).

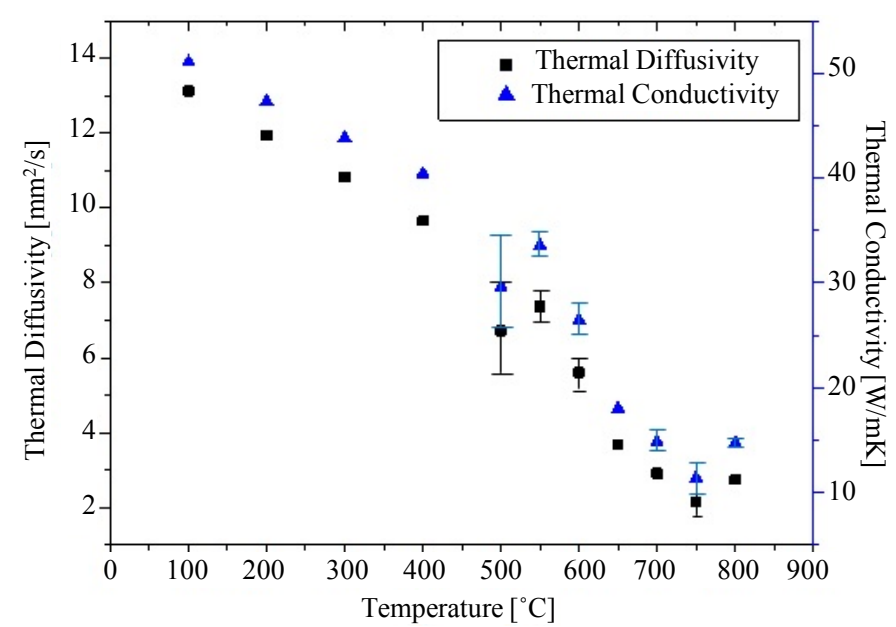

Figure 6. Measuments of the thermal diffusivity $\left[\mathrm{mm}^{2} / \mathrm{s}\right]$ and thermal conductivity $[\mathrm{W} / \mathrm{mK}]$ of theAPI $5 \mathrm{~L}$ X80 steel.

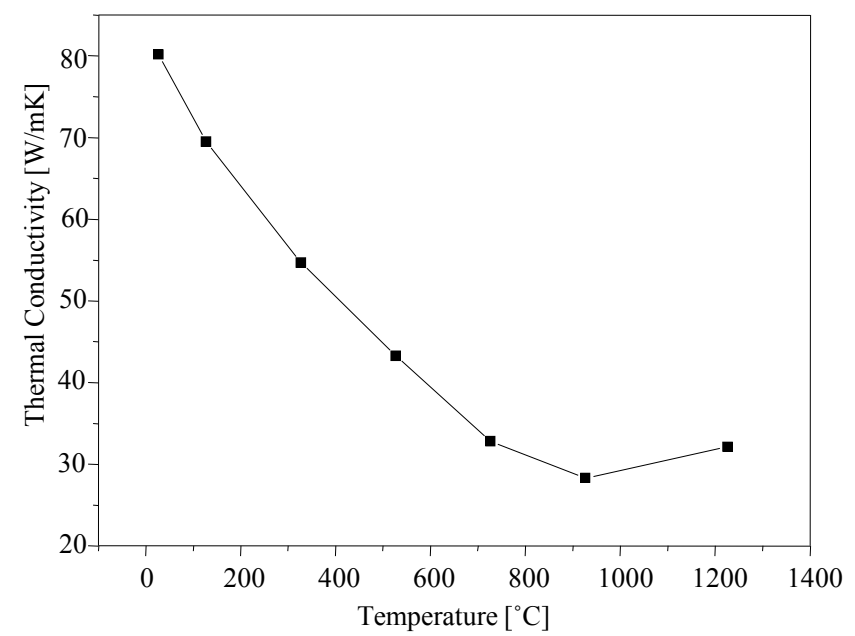

Figure 7. Obtained results of the thermal conductivity $[\mathrm{W} / \mathrm{mK}]$ of the pure iron. 
Deng [19] obtained a similar behavior $K$ versus $T$ curve, but with different values of thermal conductivity, studying a steel with carbon content of $0.15 \% \mathrm{C}$ and $0.45 \% \mathrm{C}$. The same behavior in the $K$ versus $T$ curve was also observed in the work of Tsirkas [24] in the AH 36 steel. Different results were found by Klobcar [25] studying the temperature distribution generated by GTAW welding in a H13 steel. The same occurred with Dhingra and Murphy [26] studying the temperature distribution generated by GMAW welding in a butt joint of a low carbon steel.

According to Deng [19], one must consider the effects of the flow of liquid metal on the temperature distribution in a welded joint. If this effect is neglected in the modeling, a higher temperature value will be obtained in the weld pool. Using the dual-ellipsoidal source model of Goldak [27] [28], one value above $3000^{\circ} \mathrm{C}$ can be obtained, thus very different from realistic situation. To avoid these problems in their study, Deng saw an increase in thermal conductivity to offset the effect of the flow of liquid metal in the weld pool. When the temperature is higher than the melting point, the thermal conductivity value is assumed to be approximately two times higher than that at room temperature.

Peet [29] predicted the thermal conductivity of steels had a strong significance in the behavior if the manganese, nickel, molybdenum and chromium were present. Carbon, silicon, vanadium and copper had a lower significance, while elements titanium, tungsten, niobium and aluminium had very low significance. Following these authors [29], the aluminum, with lowest significance, is a strong carbide forming, as such it may usually form second phases not affecting the thermal conductivity greatly, except by removal of carbon or nitrogen.

The numerical finite element method (FEM) can predict the temperature field along the welded component. A challenging part to provide precise numerical results is the experimental measurement of the thermophysical properties of the material, thereby causing behavior of the modeled component reflects the real behavior. If, in the numerical simulation, this set of properties is available and the generated mesh has refinement sufficient, the temperature distribution due to welding can be obtained accurately along the model, making the finite element method highly effective. The use of thermo-physical properties not belonging to the material studied provides erroneous numerical results.

\section{Conclusions}

- The dilatometric test carried out in the API 5L X80 steel showed the occurrence of phase transformations $\alpha \rightarrow \gamma$ and $\gamma \rightarrow \alpha$ during heating and cooling steps in the temperature ranges from $730^{\circ} \mathrm{C}$ to $890^{\circ} \mathrm{C}$ and $785^{\circ} \mathrm{C}$ to $685^{\circ} \mathrm{C}$, respectively. The thermal expansion coefficient remained approximately with constant value of $8.5 \times 10^{-6} \mathrm{~K}^{-1}$, however, due to the occurrence of these phase transformations during the stages of heating and cooling, the thermal expansion coefficient of steel suffer two falls reaching values $-25 \times 10^{-6} \mathrm{~K}^{-1}$ and $-50 \times 10^{-6} \mathrm{~K}^{-1}$, respectively. At the end of these transformations, the thermal expansion coefficient becomes to the value of $8.5 \times 10^{-6} \mathrm{~K}^{-1}$.

- It is observed that this material, in the temperature range $300^{\circ} \mathrm{C}$ to $1200^{\circ} \mathrm{C}$, shows minimum and maximum values of specific heat equal to $0.571 \mathrm{~J} / \mathrm{gK}$ and $1.084 \mathrm{~J} / \mathrm{gK}$ at temperatures of $300^{\circ} \mathrm{C}$ and $720^{\circ} \mathrm{C}$, respectively. The presence of this peak in the curve $C p \times T$, shows the occurrence of phase transformation $\alpha \rightarrow \gamma$ in the steel.

- The behavior of thermal diffusivity and thermal conductivity of API 5L X80 steel, in the temperature range $100^{\circ} \mathrm{C}$ to $800^{\circ} \mathrm{C}$, tends to decrease with increasing temperature, with minimum and maximum values of diffusivity equal to $3 \mathrm{~J} / \mathrm{gK}$, and $13 \mathrm{~J} / \mathrm{gK}$ at temperatures of $750^{\circ} \mathrm{C}$ and $100^{\circ} \mathrm{C}$, respectively, and thermal conductivity equal to $13 \mathrm{~W} / \mathrm{mK}$ and $52 \mathrm{~W} / \mathrm{mK}$ at the same temperatures.

\section{Acknowledgements}

We'd like to thank Calorimetry Laboratory of the Department of Physics of Pernambuco Federal University for the DSC tests, as well as to Solar Energy Laboratory of Paraiba Federal University for the laser flash tests. We also thank the CONFAB for providing the material of this study.

\section{References}

[1] Shanmugam, S., Ramisetti, N.K., Misra, R.D.K., Hartmann, J. and Jansto, S.G. (2007) Microstructure and High Strength-Toughness Combination of a New 700MPa Nb-Microalloyed Pipeline Steel. Materials Science and Engineering, 478, 26-37. http://dx.doi.org/10.1016/j.msea.2007.06.003 
[2] Shin, S.Y., Hwang, B., Lee, S., Kim, N. J. and Ahn, S.S. (2007) Correlation of Microstructure and Charpy Impact Properties in API X70 and X80 Line-Pipe Steels. Materials Science and Engineering A, 458, 281-289. http://dx.doi.org/10.1016/j.msea.2006.12.097

[3] Li, M., Brooks, J.A., Atteridge, D.G. and Porter, W.D. (1997) Thermophysical Property Measurements on Low Alloy High Strength Carbon Steels. Scripta Materialia, 36, 1356-1359. http://dx.doi.org/10.1016/S1359-6462(97)00051-1

[4] Chaowen, L. and Yong, W. (2013) Three-Dimensional Finite Element Analysis of Temperature and Strees Distributions for In-Service Welding Process. Materials and Design, 52, 1052-1057. http://dx.doi.org/10.1016/j.matdes.2013.06.042

[5] Hansen, J.L. (2003) Numerical Modelling of Welding Induced Stresses. Ph.D. Thesis. Technical University of Denmark, Kongens Lyngby.

[6] Guimarães, P.B., Pedrosa, P.M.A., Yadava, Y.P., Filho, A.V.S., Barbosa, J.M.A. and Ferreira, R.A.S. (2011) Obtaining Temperature Fields as a Function of Efficiency in TIG Welding by Numerical Modeling. Engenharia Térmica (Thermal Engineering), 10, 50-54.

[7] Guimarães, P.B., Pedrosa, P.M.A., Yadava, Y.P., Filho, A.V.S., Barbosa, J.M.A. and Ferreira, R.A.S. (2013) Determination of Residual Stresses Numerically Obtained in ASTM AH36 Steel Welded by TIG Process. Materials Sciences and Applications, 4, 268-274. http://dx.doi.org/10.4236/msa.2013.44033

[8] Deng, D. and Murakawa, H. (2006) Prediction of Welding Residual Stress in Multi-Pass Butt-Welded Modified 9Cr-1Mo Steel Pipe Considering Phase Transformation Effects. Computational Materials Science, 37, 209-219. http://dx.doi.org/10.1016/j.commatsci.2005.06.010

[9] Yaghi, A.H., Tanner, D.W.J., Hyde, T.H., Becker, A.A. and Sun, W. (2011) Abaqus Thermal Analysis of the Fusion Welding of a P92 Steel Pipe. SIMULIA Customer Conference, Barcelona, 17-19 May 2011, 622-638.

[10] Incropera, F.P. and Dewitt, D.P. (2008) Fundamentos de Transferência de Calor e Massa. 6th Edition, LTC, Rio de Janeiro.

[11] Richter, F. (1973) Die Wichtigsten Physikalishen Eigenschaften von 52 Eisenwerkstoffen, Verlag Stahleisen GmbH, Dusseldorf.

[12] Powell, R.W. and Hickman, M.J. (1946) Thermal Conductivity of a 0.8\% Carbon Steel. Journal of the Iron and Steel Institute, 154, 112-116.

[13] ASTM, E1461-01 (2001) Standard Test Method for Thermal Diffusivity by the Flash Method.

[14] Rosenthal, D. (1941) Mathematical Theory of Heat Distribution during Welding and Cutting. Welding Journal, 20, 220-234.

[15] Rosenthal, D. (1946) The Theory of Moving Sources of Heat and Its Applications to Metal Treatments. Transactions of the ASME, 68, 849-866.

[16] García De Andrés, C., Caballero, F.G., Capdevila, C. and Álvarez, L.F. (2002) Application of Dilatometric Analysis to the Study of Solid-Solid Phase Transformations in Steels. Materials Characterization, 48, 101-111. http://dx.doi.org/10.1016/S1044-5803(02)00259-0

[17] Pedrosa, I.R.V., Castro, R.S., Yadava, Y.P. and Ferreira, R.A.S. (2013) Study of Phase Transformations in API 5L X80 Steel in Order to Increase Its Fracture Toughness. Materials Research, 16, 489-496.

[18] Gery, D., Long, H. and Maropoulos, P. (2005) Effects of Welding Speed, Energy Input and Heat Source Distribution on Temperature Variations in Butt Joint Welding. Journal of Materials Processing Technology, 167, 393-401. http://dx.doi.org/10.1016/j.jmatprotec.2005.06.018

[19] Deng, D. (2009) FEM Prediction of Welding Residual Stress and Distortion in Carbon Steel Considering Phase Transformation Effects. Materials and Design, 30, 359-366.

[20] Attarha, M.J. and Sattari-Far, I. (2011) Study on Welding Temperature Distribution in Thin Welded Plates through Experimental Measurements and Finite Element Simulation. Journal of Materials Processing Technology, 211, 688694. http://dx.doi.org/10.1016/j.jmatprotec.2010.12.003

[21] Shan, X., Davies, C.M., Wangsdan, T., O’Dowd, N.P. and Nikbin, K.M. (2009) Thermo-Mechanical Modelling of a Single-Bead-on-Plate Weld Using the Finite Element Method. International Journal of Pressure Vessels and Piping, 86, 110-121. http://dx.doi.org/10.1016/j.ijpvp.2008.11.005

[22] Cape, J. and Lehman, G. (1963) Temperature and Finite Pulse-Time Effects in the Flash Method for Measuring Thermal Diffusivity. Journal of Applied Physics, 34, 1909-1913. http://dx.doi.org/10.1063/1.1729711

[23] Parker, W.J., Jenkins, R.J., Butler, C.P. and Abbott, G.L. (1961) Flash Method of Determining Thermal Diffusivity, Heat Capacity and Thermal Conductivity. Journal of Applied Physics, 32, 1679-1684.

http://dx.doi.org/10.1063/1.1728417 
[24] Tsirkas, S.A., Papanikos, P. and Kermanidis, Th. (2003) Numerical Simulation of the Laser Welding Process in ButtJoint Specimens. Journal of Materials Processing Technology, 134, 59-69. http://dx.doi.org/10.1016/S0924-0136(02)00921-4

[25] Klobcar, D., Tusek, J. and Taljat, B. (2004) Finite Element Modeling of GTA Weld Surfacing Applied to Hot-Work Tooling. Computational Materials Science, 31, 368-378.

[26] Dhingra, A.K. and Murphy, C.L. (2005) Numerical Simulation of Welding-Induced Distortion in Thin-Walled Structures. Science and Technology of Welding and Joining, 10, 528-536. http://dx.doi.org/10.1179/174329305X48301

[27] Goldak, J. and Chakravarti, A. (1984) A New Finite Element Model for Welding Heat Sources. Metallurgical Transactions $B, \mathbf{1 5}, 299-305$.

[28] Goldak, J.A. and Akhlaghi, M. (2005) Computational Welding Mechanics. Springer, New York, 30-35.

[29] Peet, M.J., Hasan, H.S. and Bhadeshia, H.K.D.H. (2011) Prediction of Thermal Conductivity of Steel. International Journal of Heat and Mass Transfer, 54, 2602-2608. 
Scientific Research Publishing (SCIRP) is one of the largest Open Access journal publishers. It is currently publishing more than 200 open access, online, peer-reviewed journals covering a wide range of academic disciplines. SCIRP serves the worldwide academic communities and contributes to the progress and application of science with its publication.

Other selected journals from SCIRP are listed as below. Submit your manuscript to us via either submit@scirp.org or Online Submission Portal.
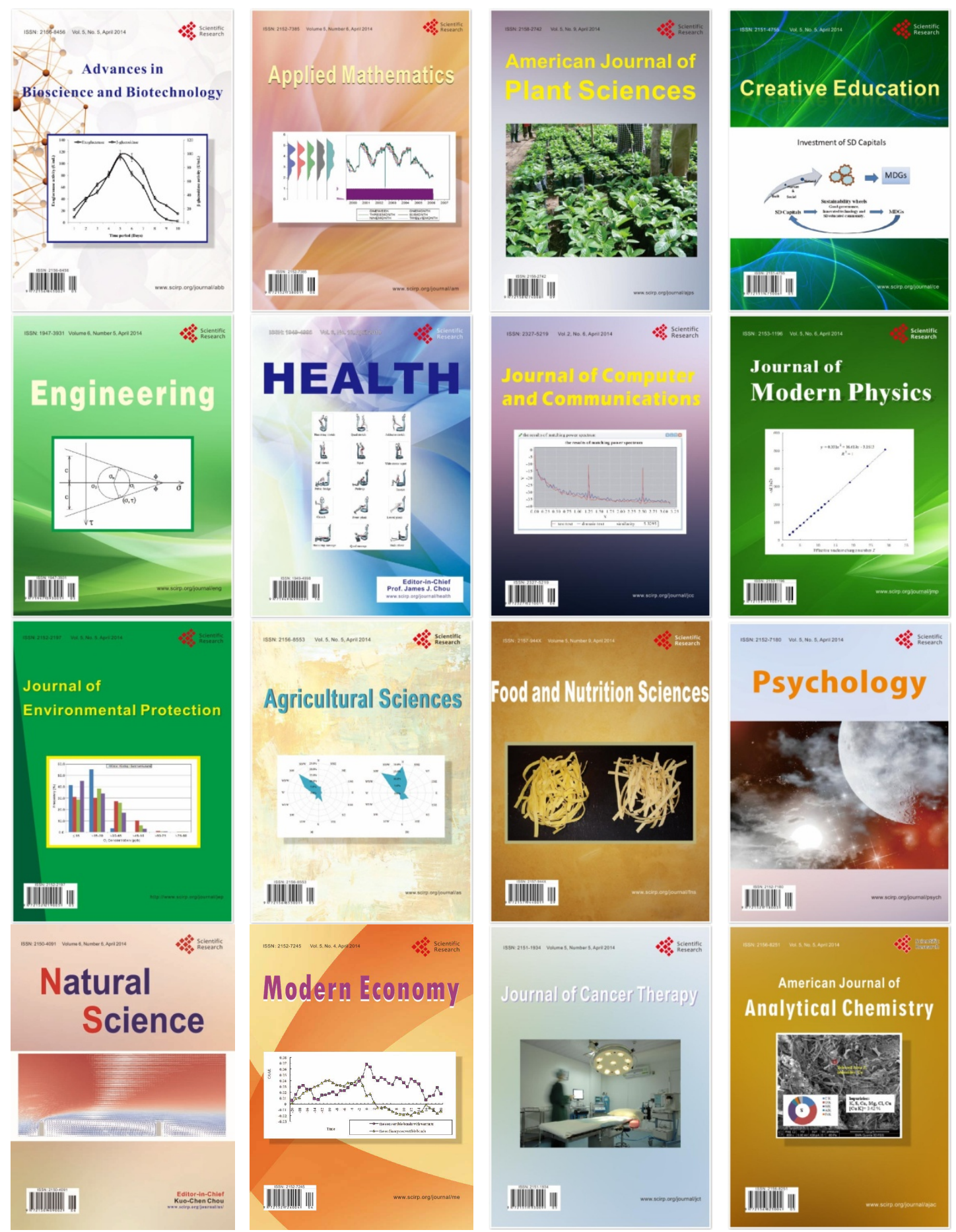